\title{
Medical and Wellness Tourism Challenges in Dead Sea Spas from Tourists' Point of View
}

\author{
Jamil Samawi ${ }^{1}$ \\ ${ }^{1}$ American University of Madaba, Madaba, Jordan \\ Correspondence: Jamil Samawi, American University of Madaba, Madaba, Jordan.
}

Received: August 10, 2017 Accepted: September 20, 2017 Online Published: September 30, 2017

doi:10.5539/ijms.v9n5p145 URL: http://doi.org/10.5539/ijms.v9n5p145

\begin{abstract}
This study aims at defining the medical tourism marketing obstacles and challenges facing Spas in the Dead Sea from the tourists' point of view. The study sample consists of 86 Jordanian tourists and Arab Countries citizens. The researcher used the analytical descriptive method. Medical tourism marketing scale has been adopted and developed from the relevant previous studies. The study suggests that the medical tourism marketing facing the Spas in the Dead Sea Region from the tourists' point of view are medium, and there is no statistically significant differences ascribed to gender and educational levels variables.
\end{abstract}

Keywords: marketing, medical and wellness tourism, Dead Sea, River Jordan, Jordan, tourism accommodation, environmental issues

\section{Introduction}

Tourism is of the most important pillars of national income. It means moving from a place to another to acquire more knowledge and leisure, and enjoy different places whether domestic or external tourism. Tourism varies depending on the touristic product; leisure, cultural, religious and medical. It is based on various components including touristic product, human resources, management, financing and marketing (Omar, 2009).

In Arabic, tourism means wondering across the globe (Abdel Aziz, 1997), while in English (tour) is a journey for pleasure in which several different places are visited (https://en.oxforddictionaries.com/definition/tour), it is taken from tourist which means someone who visits a place for pleasure and interest, usually while on holiday (http://dictionary.cambridge.org/dictionary/english/tourist), or the wondering person who visits many interested places, and tourism means move from one place to another (Abawi, 2006).

Hijab (2003) presented the tourism as temporal moving process practiced by huge number of people who leave their permanent domicile heading to other places inside their home country; it is called local domestic tourism, or to other countries; external tourism.

Marketing is one of the most important methods of promoting tourism sector. Tourism components availability without being exploited to attract tourists and marketing the tour product doesn't contribute in supporting local economy. Such successful contribution comes from marketing the tourism product (Mansour, 2011).

American Marketing Association describe marketing as planning and carrying out imagining, pricing and promotion of ideas, goods and services to complete exchange processes that satisfy population and organizations goals.

Tourism marketing is a comprehensive integrated activity that includes all exerted efforts to attract local and international tourists to pay visits to the tourism destinations inside the country by preparing tourism programs starting from contracting with tourists up to such programs completion. Tourism marketing is not limited to providing tourism services, programs, and offer them inside and abroad, rather, it starts by studying the exporting tourism markets, defining their needs of tourism products, identify available opportunities, studying the tourists' particulars, meet their needs and wishes efficiently, follow tourists up during the touristic trip, and knowing their satisfaction and impressions thereof and the problems they faced (Fyall \& Garrod, 2004).

Abdel Samei' (2006) explains tourism marketing as the administrative and technical activity practiced by touristic organizations and institutions inside and outside the country in order to develop the touristic movement, and generate tourism income; it depends on providing tourism offers which must be inflexible and unchangeable 
at the short run. It also aims at bringing out Jordan touristic image and increasing annual touristic movement by using various means to promote the tourism.

Medical and wellness tourism has been practiced since prehistory eras. Humans knew how to treat some of the diseases such as breathing and neurological problems. Humans came to know how to heal from such problems by moving to special environment where there are hot springs. The Romans mastered establishing mineral baths for medical purposes; it is the social, psychological and natural circumstances that achieve the human sound health (Abels \& Kipnis, 1998).

Medical tourism proved to generate good income as the person stays a medium or long period of time and thus spends more money if the aimed country contains mineral and sulfur water, pure and healthy atmosphere, hospitals and sanatoriums equipped with professional medical staff to help give positive tourism image to the patients who receive good treatment or heal from their diseases and make it an important tourism attraction, locally and internationally, thus developing the Spa tourism areas, employ the specialized medical staff and increase their competency and skills, employ more staff in the medical field and other paramedical fields.

Medical tourism is divided into medical tourism for patients, wellness tourism for leisure, relaxation, or disease prevention and is normally coupled with touristic programs outside the Spas.

Besides, medical tourism includes thermic tourism, treatment with sea water, hot desert sand curing, among others. Such types fall under leisure, cultural and sports tourism. It requires skilled and specialized staff due to its sensitivity towards humans (Abdel Raheem, 2009).

Medical Tourism in Jordan

Ranked first in the Middle East and fifth in the world, Jordan is on the fast track to the top in the field of healthcare. Medical tourism in Jordan has received heavy investments for hospitals and staff, and the country is working hard to attain its goal of a billion dollars in revenue for the ministry of health by 2010 , https://www.medicaltourismco.com/medical-tourism-in-jordan/.

In the period 1995-2015, tourism flows in Jordan from 1.1 million to 4.8 million (Wendt, 2016). Medical tourism has its impact on the Jordanian economy by providing employment opportunities that increase the citizens' income, the increasing demand on tourism services the prices through supply and demand. Its importance lies in the advanced health services in Jordan which stands above many similar services in the neighboring countries. Medical tourism accommodates big numbers of workforce and contributes to achieve higher added value to the economy forms of wages, profits and otherwise (Qdah \& Al Taleb, 2009).

Why Jordan as a Medical Tourism Destination?

Jordan is one of the few countries with large diplomatic relations with other countries, which allows it to travel to most of the nationalities where there is no difficulty in obtaining a visa. Quality standards in the health care sector in Jordan are high and therefore many international and local allocations have been accepted for most hospitals, especially the Accreditation Council for Health Care, which is itself accredited by ISQua, to ensure health care in the country to meet international standards. Medical tourism in Jordan has witnessed a significant increase over the years, due to the high level of experience provided by hospitals accredited by a number of doctors in leading hospitals in Jordan by the American Board or the British Fellowship, regardless of the state's activation of modern technology. Many measures to ensure that there is no language barrier for patients visiting with most of the staff where the State has been interested in training the staff in hospitals to master the English and Arabic as well as Russian to facilitate dealing with visitors.

Medical tourism leads to the revitalization and renewal of mind, body and spirit and these features are available in Jordan from healing and relaxation of the self through the elements of natural treatment from hot water rich in salts to volcanic mud to moderate weather and a beautiful nature.

Jordan has been ranked first in the Arabic world of medical tourism and fifth in the world. The number of Arab and foreign patients choosing Jordan to receive treatment is increasing as the ozone layer above sea level is a layer rich in density, according to studies conducted by the Department of Meteorology. Solar radiation is the main factor of natural healing and healing factors in the Dead Sea area and the presence of a huge amount of ultraviolet rays.

\section{Jordan Medical Achievements}

Jordan is considered a perfect destination for those seeking healing, especially those who have long suffered from incurable diseases and did not succeed in attempts to reach a full recovery in their countries, for reasons that may be related to the system of medical achievement in this country; and the efficiency of medical personnel, 
this gives due to the therapeutic medical progress and the advanced position in the field of therapeutic and hospital services, which qualified it to be ranked first in the Arab world and ranked him among the top five countries in the field of medical tourism, according to the report issued by the World Bank. Therefore, Amman has been chosen as the capital of medical tourism for 2012 due to the overlap of treatment in tourism. Jordan has a huge number of patients from Arab countries and many other countries. In view of the bloody events that have taken place in their sister countries in recent years, which has led to an increase in the number of injured, and found no better refuge than Jordan because of this golden reputation in the field of medical tourism and competitive medical services in terms of quality and cost of medical service provided by Jordanian hospitals, which enjoys the presence of distinguished medical cadres and has the latest advanced medical and technological equipment.

There is no water surface in the whole world that resembles the Dead Sea in terms of its low sea level and its salty water, although it feeds on the fresh water of the Jordan River. The Dead Sea is rich in salts and mud extracted from it, which is a successful treatment for many diseases. As well as swimming in it because of the high salinity in the water, where people do not need to know the swimming arts, because one can lie on his back and leave the Dead Sea water to bear it without bothering.

This unique resort has been attract the attention of those seeking tranquility, beauty and healing since the dawn of history. Its water has been known by famous historical figures. It continues to attract thousands of people each year and thousands of groups of local and foreign visitors seeking treatment, beauty, tranquility and warmth, thanks to its warm waters rich in sodium, potassium, bromine and manganese salts, along with a network of modern roads and numerous high-end hotels on its east coast which offers high-level hotel services as well as rest rooms, recreation areas and clean

Currently, Jordan is a medical center that has a good reputation in the Arab countries, but in the nearer future it will be replaced by Dubai's Healthcare City, this medical city will be the destination of more than half a million patients and vistors from all the countries in the Middle East and other regions in the world. In fact, Jordan same as other countries such as Cuba and Costa Rica depend on tourism as a vital sector to offer job opportunities and good income (Bookman \& Bookman, 2007).

The World Bank assigned Jordan as an important destination in the region for healthcare, and it also occupied the fifth rank as a destination for medical tourism in the world in 2010 (Stefano, 2010).

Jordan was recognized by the World Bank as the leading regional destination for healthcare, and the fifth medical tourism destination worldwide in 2010 (Stefano, 2010). Most Jordanian health-care services are endorsed by both local and global administrations. Among the wildest increasing segments within medical tourism in Jordan is the dental tourism (Al-Hammouri, 2010).

Currently, the business of Spa in Jordan is rising up to 15 percent yearly, 11 percent of this percentage comes from accommodations in spa and wellness. Over the following ten years the market of spa is expected to grow (USAID, 2009). Other countries in the region such as Lebanon and Dubai compete with each other and have ambitions in the region to be the Middle East hospital instead of Jordan (The Lebanese Council for National Health Tourism was established and in order to develop medical tourism it invest US\$500,000, among which US\$150.000 in its first month where 50 patients have come from the Arab countries) (Medical Tourism in Developing Countries Milica Z. Bookman and Karla R. Bookman, 2007).

The Dead Sea is located in the lowest basin on the surface of the earth. It is located in the valley of the Syrian-African devastation, which stretches more than 6,000 kilometers between Marash in northern Turkey and the Zambian River in South Africa. The ravine runs along the shores of the Levant at a distance of 40 to 90 kilometers in Palestine, Syria, Lebanon and the Dead Sea. The Dead Sea is located in the above-tropical, subtropical, desert and desert climates. The Dead Sea is a watershed between Palestine on the west and Jordan on the east. It extends from north to south for $78 \mathrm{~km}$ with an average width of $14 \mathrm{~km}$. Its width is reduced to only $4 \mathrm{~km}$, where towards the west appears a terrain that is called the tongue, which is almost a quarter of the South Sea separates from the rest of the sea and there is a shallow water block up between the tongue and the rest of the parts of the sea.

The Dead Sea is confined to two mountain ranges, as mentioned above: the mountains of Jerusalem and Hebron in the west, and the mountains of Balqa, Karak and Tafilah to the east, and the peaks of these mountains rise above sea level between $1,250 \mathrm{~m}$ and 1,300 $\mathrm{m}$, characterized by its steep decline in addition to the slopes that turn into sloping creeks On the shores of the Dead Sea without leaving a clear coastal spot, and close to the ends of the Dead Sea on both sides of the north and south Palestinian mountains start to move away from the sea to appear small plains include Mount Asadum in the far south, extending the mountain and reach the Dead Sea 
from the Southwest, The east side becomes a gradient, the end of the Dead Sea is in the Jordan Valley to the north of the Jericho area, and its end to the south is a wide and flat area of about $20 \mathrm{~km}$ to occupy the plain of Ghor El Safi and Wadi Araba. The area of the Dead Sea is approximately $940 \mathrm{~km} \mathrm{2,} \mathrm{and} \mathrm{its} \mathrm{basin} \mathrm{area} \mathrm{is}$ approximately $40,000 \mathrm{~km} 2$.

On the shore of the lake in Jordan and Israel there are many accommodation spots throughout the year which is an indication that there is a large scale of the tourism phenomenon in the Dead Sea. Different types of wellness and spa resorts, medical centers, shelters, guesthouses, bed-sitters, clinics, houses and holiday cabins over thousands of beds in 41 institutions in Israel and 26 in Jordan, 16 of them on the Israeli coast and 9 on the Jordanian side market themselves by appealing they have straight entree to the beach.

It is not easy to find accurate data about the number of tourists who visit the dead sea, the number of tourists who come from or Jordan from the other countries is not known, The Jordanian Ministry of Tourism and Antiquities (MOTA) state that the size of tourist movement in 2015 by the Dead Sea was 28.4 thousand people and 35.1 thousand in 2014. Out of these respectively 14.8 thousand (2015) and 16 thousand (2014) tourists were locals, 13.6 thousand (2015) and 19.1 thou-sand (2014) were foreign. Assuming that the tourists stayed for an average stay of one week, there were 198.8 thousand person-nights in 2015 and 245.7 thousand person-nights in 2014 (MOTA, 2015). The number of person-nights divided by the number of days within a year will give us an approximate statistical number of tourists resting by the Jordanian shore of the basin. It is possible to assume that there were 545 people per day (2015) and 673 people per day (2014) in a relatively small fragment of the North shore of the lake.

Israel controlled the Dead Sea and also an important portion of the western shore of the lake, the major enterprises in the tourism industry favor localizing their substances by the Dead Sea because of the administration, authority, payment and safety concerns, these circumstances can be best met on the western beach of the smaller South Basin. There are no transportation accessibility restrictions when roaming due to the comparatively short distances within Israel and a respectable system of highways

An important portion of the western shore of the lake, beside the Dead Sea Highway, is controlled by Israel. As the administration, authority, payment and safety concerns, the major enterprises in the tourism industry favor localizing their substances by the Dead Sea, but at an expanse from the Palestinian Authority territory. These circumstances can be best met on the western beach of the smaller South Basin. Due to the comparatively short distances within Israel and a respectable system of highways, there are no transportation accessibility restrictions when roaming. Likewise, a very balanced decision was to localize holiday alternatives in Jordan. Most these hotels are built on the north-east route or near the eastern beach from the bigger beach of the northern lake in Sowayma (12), nearby Madaba (11), Al-Salt (1) and in Al-Qastal (1). Only Athughrah (1) is situated east of the southern basin of the Dead Sea. Such localization is the result of easy transport availability as most tourist resorts are situated in the region of the neighboring reserve to the capital of the country.

The idea of the present study intends to explore and identify medical tourism obstacles in the Spas in the Dead Sea area.

\subsection{Problem \& Questions}

Jordan is a country that treats many chronic and non-chronic diseases and is a developed country in the field of medical tourism, several spas in Jordan use mineral water treatment, hot water falls and volcanic mud. The Kingdom has many developed hospitals, well known doctors and advanced medical network in public, private and military health sectors. The research tackled medical tourism obstacles in the Jordanian tourism sector, and the role of medical tourism in the economic sustainable development in the country.

Given the importance of the medical tourism marketing due to the availability of tourism components as the main inlet to activate and develop the tourism sectors' role in Jordan by shedding light on the realty, goals and policies of marketing the medical tourism and achievement of our country in this field and determine the most important obstacles and problems which our country faces, the study problem lies in replying the following questions:

1) What are the obstacles facing medical tourism marketing in Dead Sea Spas?

2) Are there any statistically significant differences in the medical tourism marketing obstacles in the Spas in the Dead Sea Region attributed to gender and scientific qualification variable? 


\subsection{Significance of the Study}

The study is significant theoretically and practically. The significance of this study could be summarized as follows:

1) Advise the private sector to the importance of paying attention to the medical tourism marketing and health sector in general.

2) The study importance lies in giving clear and elaborated image of the medical tourism marketing reality in Jordan, and pointing out the major problems and challenges which such sector suffers.

3) Highlighting the natural and cultural sources that Jordan possesses which could be invested and exploited in touristic and medical issues.

4) The importance of studying and analyzing the medical tourism market as well as the consumer behavior to meet his needs and wishes in the economic field.

5) Highlighting the positive effects of such sector, whether in terms of capital flow, investments increase, reducing unemployment rates, emphasizing the importance of marketing in increasing productivity for the decisions makers in Jordanian private hospitals and the benefits we may generate from medical tourism marketing.

6) The study results may enrich the scientific knowledge related to marketing and medical tourism from the point of view of the Spas staff at the Dead Sea Region.

7) The researcher hopes to benefit from the research results to determine the obstacles facing the medical tourism marketing and extensive use of tests relating thereto in the Jordanian environment.

8) The reached at results herein may be used as a starting point for researchers and learners to benefit from the current study tools, results and recommendations in future studies, especially under local studies concerned with administrative and marketing methodologies.

9) Presenting some recommendations and suggestions on the light of the outcomes of this study.

\subsection{Study Purposes}

The present study aims at:

1) Presenting integrated theoretical frame of the study variables.

2) Defining the medical tourism marketing concept and particulars.

3) Determining the obstacles facing medical tourism marketing at the Dead Sea Spas.

4) Identifying the differences in the medical tourism marketing obstacles in the Dead Sea spas that are attributed to gender and academic qualification variable.

\subsection{Study Limitations}

The outcomes of this study could be defined and generalized on the light of the following limitations:

- The Sample: The study included random sample from population study, in particular the Spas in the Dead Sea Region.

- Study tools: The outcomes of this study are defined by the availability of the following tools:

The Medical tourism marketing scale; in terms of setting up, development, reliability and stability of each scale

\subsection{Study Limits}

The limits of the present study include the following:

1) Human limits: Tourists in Dead Sea Region.

2) Spatial limits: The Hashemite Kingdom of Jordan—Dead Sea Region

3) Time limits: 2017

\subsection{Conventional \& Procedural Definitions}

\subsubsection{Tourism}

UNWTO defines the tourism as a group of relationships and services originating from travel and residence to the limit that the tourist neither needs permanent residence nor payable wages. (UNWTO, 2017) 


\subsubsection{Marketing}

It includes all the company activities; pre, current or after the production process (Al Zahraa, 2016), rather than being sale, advertising, direct mail, advertising brochures or any other things which people consider marketing.

- It has its procedural definition; degree where the sample population attain through their response to the study scale items.

\subsubsection{Medical Tourism}

The International Union of Official Travel Organization defines the medical tourism as benefiting of medical preparations and facilities that ease using the country natural resources, especially mineral waters (Mathieson \& Wall, 1984). Therefore it is type of modern tourism that provides human psychological and physical therapy.

- $\quad$ The procedural definition is the degree attained by the sample population through their response to the study scale items.

\section{Previous Studies}

Through the desk survey of management literatures, the researcher concluded a number of studies related to medical tourism marketing:

Suhaimat (2012) conducted a study on the impact of medical tourism on the national economy in Jordan from the tourism sector staff point of view. The study sample consisted of (150) employees who work in Dead Sea Spas. The study tool included (25) items. The outcomes showed statistically significant differences between pricing policy in the Spas and developing medical tourism in Jordan, in addition to statistically significant differences between medical tourism and the national economy growth.

Mansour (2011) conducted a study to identify the local touristic attraction obstacles and its role in setting up tourism marketing strategy from offices' owners and tourists' point of view. For this purpose, the researchers used questionnaire consisting of (25) items distributed to a sample of (100) office owners in Palestinian Governorates in the West Bank. The study suggests that touristic attraction components are medium and affect the marketing strategy structure to promote domestic tourism in Palestine from the tourist offices owners' and tourists' point of view at a rate of $(65 \%)$. Moreover, the economical conditions effect is medium at setting up marketing strategy to promote the domestic tourism in Palestine from the tourist offices owners' and tourists' point of view at a rate of $(51.4 \%)$. In addition, the political conditions play a great role in setting up marketing strategy to promote domestic tourism in Palestine from the tourism offices owners' and tourists' point of view at a high rate of $(74.6 \%)$. Furthermore, the academic qualification of tourism staff effects setting up marketing strategy to promote the domestic tourism in Palestine from the tourism offices owners' and tourists' point of view at a high rate of $(77.4 \%)$.

Abed Al Hussein (2009) conducted a study aimed at identifying the usage of modern communication means in marketing tourism service and the electronic quality thereof. This research tackled E-trade and E-marketing and focused on tourism service e-marketing and the relation thereof to the quality marketing of such service. The study included (14) tourist offices and companies in Amman-Jordan. A questionnaire of (19) questions was designed, and the study sample included (20) employees of these tourist companies. Moreover, the study adopted four tested assumptions by analyzing the sample population replies. The study suggests that there is a relationship between tourist service e- marketing and quality in the tourisms companies .

Qdah \& Taleb (2009) conducted a study to identify the importance of medical tourism sector being one of the tourism different forms in general and to recognize the impact of the relationship that may affect the Jordanian national economy as the tourism sector is part of the sustainable development processes sectors. Study sample consisted of (175) members in private hospitals staff in Jordan. The study suggests that there is no relationship between pricing policies in Jordanian health sector and medical tourism development in Jordan, and further that there is no relation between the Jordanian labor competency in the health sector and the medical tourism development in Jordan.

Al Msharbash (2008) conducted a study to analyze the factors affecting tourists' satisfaction of the medical tourism and health services offered to tourists and their companions in Jordan. The study sample consisted of (1000) questionnaires distributed to a number of private hospitals in Amman. The outcomes suggest the availability of medical tourism components in Jordan from the tourists' point of view, including Jordan geographical location as to Arab tourists seeking medical treatment in Jordan as well as climate diversity in winter season being one of such components, in addition to the distinguished natural features, the availability of specialized Spas and diversified medical services. 
Cultural attraction is affected by religion because patients from different countries may be affected by their creed when they select a destination. By this way Jordan draws Muslims from the Arab world, and recently some countries did their efforts to invite patients from Islamic countries and countries in the Middle East such as Malaysia. These efforts contain guarantees that patients will obtain delicate treatment with admiration to their spiritual compliances such as prayers and food. The language of medicine and investigation smoothness in world languages, especially those in which medicine and biomedical research is being shown, is a clear benefit for states in their search of medical tourism. English has become the lingua franca in general, and specifically with admiration to practical research. As a result, India and the Philippines have an advantage over other countries as English is one of their official languages and the only one that is used outside its boundaries. For the same cause, Arab-speaking Jordan has a benefit when it comes to inviting foreign Arab speakers to its hospitals (Dadpour \& Sirat, 2009).

Al-Tai (2002) conducted a study to identify the role of social marketing mechanisms which is the key of marketing strategies success which may be employed in the tourism industry, in addition to defining the positive and negative aspects that impact marketing activities of hosting institutions through applying social marketing mechanisms in such industry. The research was carried out depending on the analytical theoretical method of concepts and assumptions suppositions that tackled such subject. The study suggests that tourism industry is a human and social interaction industry, in addition to the known economic dimensions of such industry.

Wendt (2016) concluded that the attractiveness is heightened by its closeness to other locations of attention, such as the Jewish fortress at Masada, Jericho, Qumran, where the Dead Sea Scrolls were found, as well as Petra, Madaba and Al-Karak on the Jordanian side of the Dead Sea with the valuation that the Dead Sea along with Jerusalem belongs to one of the most well-known areas visited by visitors in Israel. High salinity and a microclimate create perfect circumstances for the progress of medical tourism and health resorts.

\section{Method \& Procedures}

\subsection{Study Methodology}

The researcher used herein the correlative descriptive methodology which suits the hereto purposes. This study included description of its population, sample, tools, procedures, variables, and statistical methods employed in analyzing its results, which are considered the best to display the reality of the tackled subject.

\subsection{Study Sample \& Population}

The study population consists of all tourists visiting the Dead Seal Spas. Total targeted number is (260) tourists of both genders. The researcher has selected random sample from the study population rated at $(33 \%)$ of total number; i.e., (86 tourists).

\subsection{Study Tool}

The researcher developed medical tourism marketing scale derived from previous studies of concern; i.e., Shuhaimat, 2012; Al Zarhaa, 2016; Qdah \& Taleb, 2009; Mansour, 2011. The researcher used the tool to measure obstacles degree in terms of medical tourism marketing in the Hashemite Kingdom of Jordan in order to achieve the outcomes. The scale consists of 14 items, to be replied by the students on the light of five-step scale (strongly agree: (5 scores), agree: (4 scores), neutral: (3 scores), disagree ( 2 scores), and strongly disagree: (1 score).

\subsection{Tool Reliability}

The employed tool herein has been presented to a group of competent academics in management and marketing to verify the tool suitability as to the test items as well as study purposes and language easiness. The academics were requested to discuss each Test item in terms of representing the variables, fitness to the sample population category and linguistic drafting of test items. The researcher ignored items which three academics or more considered as weak. The researcher also applied the scale on a pilot sample from both study population and others consisted of 15 tourists to be aware of study field aspects, calculating the stability and reliability significances to confirm its fitness.

In order to extract the internal consistency coefficients of the respective scale, the correlation coefficients of scale items with the total degree in initial sample other were extracted from outside the study sample consisting of 15 tourists. The correlation coefficient herein represents reliability coefficient for each item as correlation coefficient between each item and total degree. Items correlation coefficients with the tool ranged from 0.37-0.81). The following table illustrates the foregoing: 
Table 1. Correlation coefficients between the items \& total score on medical tourism marketing scale

\begin{tabular}{llll}
\hline Item No. & Correlation coefficient with the tool & Item No. & Correlation coefficient with the tool \\
\hline 1 & $* * 0.760$ & 8 & $* 0.384$ \\
2 & $* * 0.542$ & 9 & $* 0.419$ \\
3 & $* 0.382$ & 10 & $* 0.423$ \\
4 & $* * 0.510$ & 11 & $* * 0.447$ \\
5 & $* 0.442$ & 12 & $* 0.424$ \\
6 & $* * 0.703$ & 13 & $* * 0.809$ \\
7 & $* * 0.444$ & 14 & $* * 0.540$ \\
\hline
\end{tabular}

Note. * Statistical coefficient at level (0.05). ** Ditto $(0.01)$.

Table 1 Displays that items correlation coefficients with total score was statistically coefficient at levels $\alpha=(0.05)$ and (0.01), neither of which were omitted. This indicates that the scale fits to measure medical tourism marketing in Spas, from tourists' point of view. The foregoing confirms that the scale reliability is high and suitable to this study purposes.

As far reliability is concerned, the researcher calculated the internal consistency reliability coefficient by employing Cronbach's Alpha equation; which recorded (0.86), which is a high level and thus this value is considered suitable to the purposes of this study.

\subsection{Study Variables}

(Medical tourism marketing, gender, academic level)

\subsection{Statistical Processing}

The researcher employed Excel program in data entry and tabulation. SPSS was employed in various statistical analyses. The researcher further used statistical methods represented by arithmetic means, standard deviations, and correlation coefficients.

\section{Discussing the Study Outcomes}

The study outcomes; represented by detecting the medical tourism marketing's obstacles in Spa, shall be displayed based on some variables; gender and academic level

\subsection{Personal Particulars}

Following are some particulars of the survey unit depending on the personal particulars:

Table 2. Survey unit population per gender

\begin{tabular}{llll}
\hline Gender & Number & $\%$ & Rank \\
\hline Male & 53 & $62 \%$ & 1 \\
Female & 33 & $38 \%$ & 2 \\
Total & 86 & $100 \%$ & \\
\hline
\end{tabular}

The forgoing table displays that male tourists form the highest percentage of the sample with a total number of (53) males at (62\%); while female category was (38) persons at (38\%) of total sample population.

Table 3. Distributing sample population per the academic level

\begin{tabular}{llll}
\hline Academic level & Number & $\%$ & Rank \\
\hline Diploma or less & 13 & $15 \%$ & 3 \\
Bachelor degree & 49 & $57 \%$ & 1 \\
Postgraduate & 24 & $28 \%$ & 2 \\
Total & 86 & $100 \%$ & \\
\hline
\end{tabular}

The forgoing table displays that tourists holding Bachelor degree form the highest percentage of the sample total rated by $(57 \%)$, followed by postgraduate category at (28\%) then holders of diploma or less at $(15 \%)$.

First: What is the availability degree of medical tourism marketing obstacles in Spas?

In reply to this question, The Researcher have extracted arithmetic means, standard deviations, level and rank of 
sample population response to the items of the medical tourism marketing scale as displayed in table 4 hereinafter.

Table 4. Arithmetic means, standard deviations and ranks of medical tourism marketing scale

\begin{tabular}{|c|c|c|c|c|c|}
\hline Serial & Items & Standard deviation & Arithmetic mean & Degree & Rank \\
\hline 1 & Lack of utilities and related services; cleaning and repairs & 1.35 & 3.16 & Medium & 5 \\
\hline 2 & Disrespect time or agreed upon promises & 1.29 & 3.19 & Medium & 4 \\
\hline 3 & $\begin{array}{l}\text { Touristic culture unavailability at the Dead Sea population } \\
\text { and their minor outreach of touristic places }\end{array}$ & 1.12 & 3.24 & Medium & 3 \\
\hline 4 & Unavailability of tourist buses and five stars hotels & 1.27 & 3.03 & Medium & 9 \\
\hline 5 & $\begin{array}{l}\text { Concerned entities ignorance of such attractions and } \\
\text { obstacles faced by medical tourism investors. }\end{array}$ & 1.36 & 3.15 & Medium & 6 \\
\hline 6 & $\begin{array}{l}\text { Lack of service quality offered in the centers, and poor } \\
\text { marketing }\end{array}$ & 1.49 & 2.97 & Medium & 12 \\
\hline 7 & $\begin{array}{l}\text { Absence of security and necessary guarding in the tour } \\
\text { areas }\end{array}$ & 1.51 & 2.91 & Medium & 14 \\
\hline 8 & $\begin{array}{l}\text { Offered services by Spas are of high efficiency and quality } \\
\text { and within required specifications }\end{array}$ & 1.31 & 3.05 & Medium & 8 \\
\hline 9 & $\begin{array}{l}\text { Lack of commitment as to the declared medical tourism } \\
\text { program, bad management and directions }\end{array}$ & 1.46 & 3.1 & Medium & 11 \\
\hline 10 & $\begin{array}{l}\text { The Spas goals are focused on commercial rather than } \\
\text { medical. }\end{array}$ & 1.38 & 3.32 & Medium & 2 \\
\hline 11 & $\begin{array}{l}\text { Lack of accommodations and transportation means are } \\
\text { under required level }\end{array}$ & 1.29 & 3.02 & Medium & 10 \\
\hline 12 & $\begin{array}{l}\text { The Spas disavow from its legal mission and contractual } \\
\text { conditions }\end{array}$ & 1.22 & 2.94 & Medium & 13 \\
\hline 13 & Lack of qualified Human cadre & 1.21 & 3.09 & Medium & 7 \\
\hline \multirow[t]{2}{*}{14} & $\begin{array}{l}\text { Absence of media, advertising, especially promotion } \\
\text { efforts of the Dead Sea Region }\end{array}$ & 1.46 & 3.59 & Medium & 1 \\
\hline & Total scale & & 0.77 & & 3.14 \\
\hline
\end{tabular}

Table 4 indicates medium degree of all the items of the medical tourism marketing scale. Such fact has been derived from the study sample replies. Item No. 14; "Absence of security and guarding necessary for the zone and maintaining thereof" acquired the highest arithmetic mean at (3.59) while item No. 7; touristic culture weakness at Dead Sea Region and their outreach as to touristic places history, generated the lowest arithmetic mean at (2.91), while total arithmetic mean of the medical tourism marketing scale (3.14) at standard deviation of (0.77), at medium degree. The researcher concluded that obstacles availability degree of the medical tourism marketing obstacles among study sample came at medium degree.

The foregoing is ascribed to many factors and problems; in terms of technical knowledge shortage, developmental activities weakness, common outreach, shortage of touristic infrastructure and investment therein and security challenges. All of the foregoing does not prevent us to ignore the medical tourism qualifications available in the Hashemite Kingdom of Jordan, especially in the Dead Sea being the lowest zone on the earth. It occupies strategic location, beautiful sceneries, and intensive salty waters which is enriched by medical materials and golden sand. Dead Sea waters differ from other natural waters as it contains several minerals such as Calcium \& Potash. It is also characterized by its distinguished traditions and features. All of the above contributed to classify this zone as important station to attract and enrich medical tourism. This area needs more concern from stakeholders to present thereof in a way that suits its nature and the service it may offer.

Second: Are there any statistically significant differences in the medical tourism marketing obstacles in the Dead Sea Spas that are ascribed to gender and academic qualification variable?

In reply to the above question, the researcher have calculated arithmetic means and standard deviations of the sample population per gender and academic level, as displayed in table No. 5 hereinafter. 
Table 5. Arithmetic means and standard deviations of gender and academic level variable

\begin{tabular}{llllll}
\hline Variable & & Arithmetic mean & Number & Rank & Standard deviation \\
\hline Gender & Male & 3.31 & 53 & 1 & 0.47 \\
& Female & 3.06 & 33 & 2 & 0.73 \\
\hline Academic level & Diploma or less & 2.95 & 13 & 3 & 0.82 \\
& Bachelor degree & 3.16 & 49 & 1 & 0.60 \\
& Postgraduate & 3.06 & 24 & 2 & 0.74 \\
\hline
\end{tabular}

Table 5 displays that male category obtained the highest arithmetic mean in terms of gender variable, at (3.31). Besides tourists holding Bachelor degree obtained the highest arithmetic mean in terms of academic level, at (3.16).

In order to verify the statistically significant differences between the arithmetic means as to the medical tourism marketing obstacles, in terms of gender and academic level variables, ANOVA test was conducted, as presented in the following table 6 .

Table 6. ANOVA test to measure gender and academic level variables impact

\begin{tabular}{|c|c|c|c|c|c|c|c|c|}
\hline \multicolumn{2}{|c|}{ Medical tourism marketing } & \multirow{2}{*}{$\begin{array}{l}\text { Sum of squares } \\
0.198\end{array}$} & \multirow{2}{*}{$\begin{array}{l}\text { Degrees } \\
\text { Freedom } \\
1\end{array}$} & of & \multirow{2}{*}{$\begin{array}{l}\begin{array}{l}\text { Mean } \\
(\mathrm{MS})\end{array} \\
0.066\end{array}$} & \multirow[t]{2}{*}{ squares } & F value & $\begin{array}{l}\text { Statistical } \\
\text { significance }\end{array}$ \\
\hline Gender & Between groups & & & & & & 0.313 & 0.816 \\
\hline & Within groups & 19.430 & 85 & & 0.211 & & & \\
\hline & Total & 19.628 & 86 & & & & & \\
\hline \multirow[t]{3}{*}{ Academic level } & Between groups & 0.543 & 1 & & 0.54 & & 0.384 & 0.765 \\
\hline & Within groups & 23.197 & 85 & & 0.339 & & & \\
\hline & Total & 24.740 & 86 & & & & & \\
\hline
\end{tabular}

Note. ${ }^{* *}$ Statistical significance at level $(\alpha=0.05)$.

Table 6 above, indicates the absence of statistically significant differences in the medical tourism marketing obstacles that ascribed to gender where $F$ calculated value is $(0.313)$ at significant level $(0.816)$. Also no statistically significant difference were noticed in the medical tourism marketing obstacles that are attributed to academic level variable where $\mathrm{F}$ calculated value is (84.3), at significant level (0.765), which is not statistically significant at level $(\alpha=0.05)$.

\section{Recommendations}

Jordan has spent widely in the innovation of public hospitals and medical schools, as a result, many new private hospitals have been established, all with state-of-the-art technology while at the same time producing motivations for both local and foreign private investment in the health sector. In Jordan, the government will implement tax inducements for foreign and domestic stockholders in that segment and assured enormous tourism infrastructure plan. With the aim of endorsing and dispersal information on its medical potentials, Jordan is discussing the opportunity of employing medical diplomats in their embassies across the world. The lack of adequate private sector guidance is regarded as the major difficulty to the expansion of the tourist segment in Jordan. With tourists such as Bahrain and Dubai, has sought out links to health centers across North America, Jordan is competing to recall its location as the Middle Eastern capital of medical tourism. As a result, its top efficient hospitals all have computerized links to health centers in North America (Jordan's King Hussein Medical Center, linked to the Mayo Clinic in the United States for consultations and tele-education). Authorities in Jordan, as well as in other destination countries, have been conscious of and are aware of the fact that the enormous potential of medical tourism can be destroyed by something as basic as water and power. U.S., UK and many countries citizens do not require visas to travel to the countries under study. A tourist visa can be issued at the border in Jordan.

It is also required to spend more on marketing and promotional activities whether by the government or by other stakeholders such as Jordan Hospital Association, Jordan Medical Association, Jordan Hotel Association, Jordan Tourism Board, or by medical doctors and spa owners to increase the knowledge and awareness regarding medical tourism in Jordan, the presence of professional hands in this field and the availability of various locations and treatments in Jordan in general and the Dead sea in particular.

The Study suggests the following recommendations 
1) Support and enhance medical tourism in Spas in Dead Sea Region, as it is considered as future winner in medical tourism issue. He who owns quality owns the tourist.

2) Activate and facilitate tourism movement through supplying transportation means and facilities to various medical tourism areas, and in the same time minimize the entry procedures to the country via issuing visas in the airports, and associating the embassies to promote the Jordanian tourism.

3) Diversifying Jordanian Medical tourism product, as this shall contribute to promote all other touristic issues and increasing the tourists' numbers. This requires carrying out marketing activities to attract those concerned of tourism in Jordan.

4) Working to spread security in the country, which is the vital factor for successful tourism whatsoever type is at the local and foreign levels.

5) Developing the infrastructures and superstructures such as hotels of all categories which have to be in line with all tourists' levels and also establishing new airports and suitable highways networks to facilitate reaching the touristic zones in calm and suitable manner. (for example: The Mövenpick Resort and Spa at the Dead Sea in Jordan is touted as the only place in the world where beneficial rays from the sun extend to this level below the sea, and virtually no UV radiation can reach the skin causing skin problems, especially psoriasis), and it should be noted that the German health insurance pays for single occupancy at the Mövenpick Resort and Spa Dead Sea in Jordan for those who suffer from psoriasis and other skin conditions, as such treatment is not available in Germany, on THE OTHER HAND (King Hussein Cancer Center, the only internationally accredited hospital in Jordan, offers the most up-to-date cancer treatments in the region, (Bookman \& Bookman, 2007).

\section{References}

Abawi, Z. (2006). Touristic and Hotel Terms Dictionary, Arabic-English. Amman, Jordan: Knowledge Treasures Publications.

Abdel Samei', S. (2006). Scientific Basis of Tourism and Hotel Marketing, Some Arab Countries Practices. Morocco Geography Magazine, Arab Organization for Administrative Development.

Abed Al Hassan, S. (2009). Tourism service e-marketing and its impact on the service quality in tourism agencies. Faculty of Education Magazine (7th ed.).

Abels, D., \& Kipnis, V. (1998), Bioclimatology and Balneology in Dermatology: a Dead Sea perspectives. Clinics in Dermatology, 16, 695-698. https://doi.org/10.1016/S0738-081X(98)00059-5

Al Qdah, H., \& Al Taleb, G. (2009). Medical Tourism, and its Impact on the Jordanian National Economy from Jordanian Hospitals Employees Perspective, Site Study. Al Qadisiah Science Magazine, 11(4), 60-97.

Al Zahraa, O. (2016). Tourism Marketing Problem in the Southern Area, a Case Study and Bashar Mechanism as a Model. Unpublished Masters Dissertation, Wahran University 2.

Al-Hammouri, F. (2010). Medical Tourism the Fastest Growing Industry Overview with a focus on the Jordanian Experience. Retrieved from www.treatment-abroud.ru

Al-Tai, H. (2002). Community Concept of Marketing in Tourism Industry, 1st. Seminar for Marketing in the Arab World (Reality and Development Scopes), Al Shajah, UAE 15-16 October 2002.

Bookman, M., \& Bookman, K. (2007). Medical Tourism in Developing Countries (1st ed.). London: Palgrave Macmillan. https://doi.org/10.1057/9780230605657

Cambridge dictionary. (2017). Retrieved from http://dictionary.cambridge.org/dictionary/english/tourist

Dadpour, R., Mohamed, B., \& Sirat, M. (2009). An analysis of the gap between cultural and religious tourism in Iran, a case study on Mashhad. In Proceedings of 2nd National Symposium on Tourism Research, University Sains Malaysia, Penang, Malaysia 18 July 2009, Theories and Applications (pp. 76-82). Social Transformation Platform.

Fyall, A., \& Garrod, B. (2004). Tourism marketing: A Collaborative approach, Aspects of Tourism. Library Congress Cataloging \& Brian Garrod.

Hazbun, W. (2002). Mapping the Landscape of the "New Middle East": The Politics of Tourism Development and the Peace Process in Jordan. In G. Joffe (Ed.), Jordan in Transition 1990-2000 (p. 341). New York: Palgrave.

Health \& Wellness Tourism, a Focus on the Global Spa Experience, Case Studies, Routledge Tourism. (2017). Retrieved from https://www.crcpress.com/rsc/downloads/Health_Wellness_Tourism_FB_final.pdf 
International Tourism Organization. (2005). UN organization's statistics General Assembly of tourism and national heritage 2015, Tourism Marketing, KSA.

Maharbash, D. (2008). Factors affecting Tourist's Satisfaction of Medical Tourism in Jordan. Unpublished Masters Dissertation, University of Jordan.

Mansour, M. (2011). Local Touristic Attraction Obstacles and its Role in Building Tourism Marketing Strategy. Unpublished Dissretation, Al Najah National University.

Mathieson, A., \& Wall, G. (1984). Tourism: economic, physical and social impacts. Annals of Association of Economic Geographer, 30(2), 157-160.

$\begin{array}{lllll}\text { Medical Tourism } & \text { (2017). J } & \text { Retrieved }\end{array}$ https://www.medicaltourismco.com/medical-tourism-in-jordan/

Omar, G. (2009). Tourism Movement in South Area of the West Bank, Palestine, Mishawi Center for Studies and Research.

Oxford dictionary. (2017). Retrieved from https://en.oxforddictionaries.com/definition/tour

Shannini, A. R. (2010). Tourism Marketing Role in Refreshing the Traditional Industry and Crafts, Site Study, Ghardaiah City Case. Unpublished Dissertation, Abu Baker Balgayed University.

Tawfic M. A. A. (1997). Tourism Industry. Amman, Jordan: Wahran House Publication.

Wendt, J. A. (2016). Tourism development challenges on the Dead Sea shore. Limnological Review, 16(2). https://doi.org/10.1515/limre-2016-0011

\section{Appendix A}

\section{Study Tool}

\section{First: Personal Data}

You are kindly requested to answer the following items by marking (X) against each answer which is in line with your reality with each question:

Sex $€$ Male $€$ Female

\section{Academic Level}

$€$ Diploma or less $€$ Bachelor degree $\quad €$ Postgraduate

Second: Pleas answer the following items by marking $(\mathrm{X})$ in the selection box that suits or applies to you

\section{Medical Tourism Marketing Scale}

\begin{tabular}{|c|c|c|c|c|c|c|}
\hline Serial & Items & Agree & Strongly agree & Neutral & Disagree & Strongly disagree \\
\hline 1 & $\begin{array}{l}\text { Lack of utilities and related services; cleaning } \\
\text { and repairs }\end{array}$ & & & & & \\
\hline 2 & Disrespect time or agreed upon promises & & & & & \\
\hline 3 & $\begin{array}{l}\text { Touristic culture unavailability at the Dead Sea } \\
\text { population and their minor outreach of } \\
\text { touristic places }\end{array}$ & & & & & \\
\hline 4 & $\begin{array}{l}\text { Unavailability of tourist buses and five stars } \\
\text { hotels }\end{array}$ & & & & & \\
\hline 5 & $\begin{array}{l}\text { Concerned entities ignorance of such attractions } \\
\text { and obstacles faced by medical tourism } \\
\text { investors. }\end{array}$ & & & & & \\
\hline 6 & $\begin{array}{l}\text { Lack of service quality offered in the centers, } \\
\text { and poor marketing }\end{array}$ & & & & & \\
\hline 7 & $\begin{array}{l}\text { Absence of security and necessary guarding in } \\
\text { the tour areas }\end{array}$ & & & & & \\
\hline 8 & $\begin{array}{l}\text { Offered services by Spas are of high efficiency } \\
\text { and quality and within required specifications }\end{array}$ & & & & & \\
\hline 9 & $\begin{array}{l}\text { Lack of commitment as to the declared medical } \\
\text { tourism program, bad management and } \\
\text { directions }\end{array}$ & & & & & \\
\hline
\end{tabular}




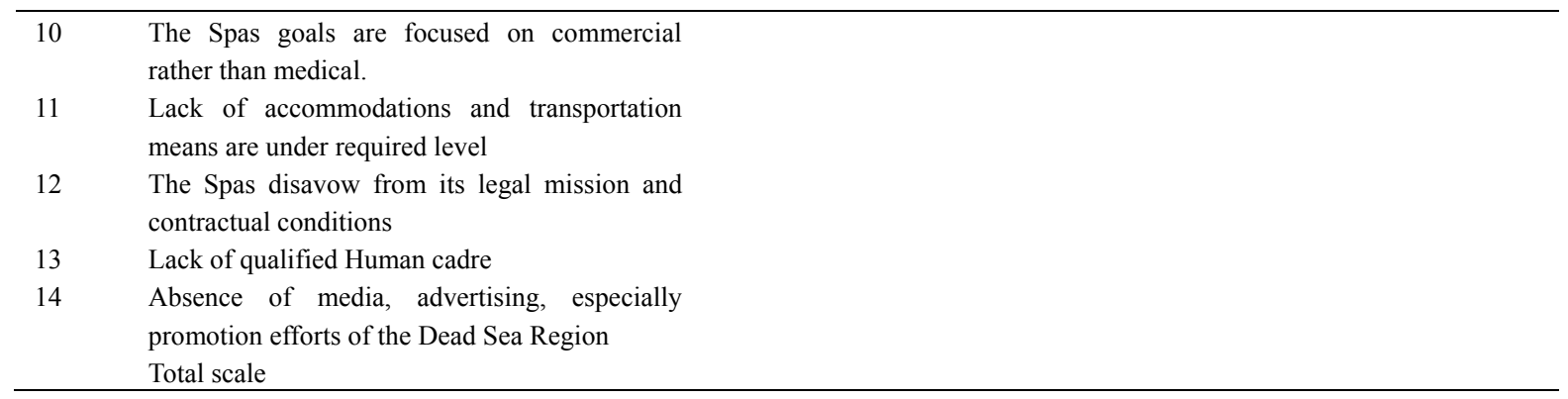

\section{Self-Efficacy Scale}

\begin{tabular}{|c|c|c|c|c|c|c|}
\hline Serial & $\begin{array}{l}\text { Items } \\
\text { Emotional field }\end{array}$ & Agree & Strongly agree & Neutral & Disagree & Strongly agree \\
\hline 1 & I control my feelings & & & & & \\
\hline 2 & I can relax once I want to & & & & & \\
\hline 3 & $\begin{array}{l}\text { I can deal in efficient manner with life pressures that } \\
\text { face me }\end{array}$ & & & & & \\
\hline 4 & $\begin{array}{l}\text { I do not control my acts once I become angry } \\
\text { Social field }\end{array}$ & & & & & \\
\hline 5 & $\begin{array}{l}\text { I can establish and maintain good relations with my } \\
\text { relatives }\end{array}$ & & & & & \\
\hline 6 & I admire and respect my friends & & & & & \\
\hline 7 & I can forgive others for their bad acts towards me & & & & & \\
\hline 8 & $\begin{array}{l}\text { I can acquire others love easily } \\
\text { Determination and perseverance }\end{array}$ & & & & & \\
\hline 9 & I can carry out plans I set forth to do certain work & & & & & \\
\hline 10 & $\begin{array}{l}\text { I don't leave missions and works before being } \\
\text { completed }\end{array}$ & & & & & \\
\hline 11 & $\begin{array}{l}\text { I enjoy patience when I face difficult stands and } \\
\text { situations }\end{array}$ & & & & & \\
\hline 12 & I work diligently if I fail to do certain work & & & & & \\
\hline 13 & $\begin{array}{l}\text { I do not classify arts; drawing and music and theater } \\
\text { as time wasters }\end{array}$ & & & & & \\
\hline 14 & I enjoy general wide information & & & & & \\
\hline 15 & I learn how to deal with things in quick manner & & & & & \\
\hline 16 & $\begin{array}{l}\text { I wish to understand all things function } \\
\text { Academic Field }\end{array}$ & & & & & \\
\hline 17 & I can perform my academic duties in due time & & & & & \\
\hline 18 & I like scientific subjects in my study & & & & & \\
\hline 19 & I can set plans for my postgraduate study & & & & & \\
\hline 20 & $\begin{array}{l}\text { I don't face difficulty in utilizing the available } \\
\text { sources to employ in my studies. }\end{array}$ & & & & & \\
\hline
\end{tabular}

\section{Copyrights}

Copyright for this article is retained by the author, with first publication rights granted to the journal.

This is an open-access article distributed under the terms and conditions of the Creative Commons Attribution license (http://creativecommons.org/licenses/by/4.0/). 